\title{
The monster that is medicine
}

\section{Dr Golem: How to Think about Medicine by Harry Collins \& Trevor Pinch University of Chicago Press: 2005. 280pp. $\$ 25$}

W.F. Bynum

Having told us how to think about science (The Golem, Cambridge University Press, 1993) and technology (The Golem at Large, Cambridge University Press, 1998), Harry Collins and Trevor Pinch turn their attention to an even softer target: medicine. Readers of the previous two books will be familiar with the structure: a series of case studies, each based on a couple of principal sources, with linking commentary. They will also know that the series takes its title from a creature of Jewish mythology. Golems were powerful man-made beings that would follow orders, but they were a bit thick and did not know their own strength, and so were potentially dangerous. Collins and Pinch have never sought to teach their readers science, technology or medicine - merely how to think about these complex subjects, each of which, they argue, has golem-like characteristics.

For medicine, they invite us to consider eight topics, each with wider implications for the current state of medicine, both as science and as art (or, as they prefer to call it, succour). The translation of medical science into dinical art is rarely easy. For one thing, most medical practitioners, although trained in science, are not scientists, nor do their daily duties encourage them to be. In addition, the placebo effect - much studied but not easily explained by science - colours much of medical practice and both doctors' and patients' unconscious evaluation of their encounters. Collins and Pinch argue that the placebo effect is the hole in the heart of medicine, making the assessment of therapeutic interactions and the introduction of new drugs problematic.

Later chapters describe the difficulty of uncovering bogus doctors (those practising without qualifications); the diagnostic variability among 'real' doctors when confronted with such things as enlarged and inflamed tonsils; the problem of contested diseases such as chronic fatigue syndrome, Gulf War syndrome and fibromyalgia; the dubious effectiveness (but sacrosanct position) of cardiopulmonary resuscitation; and the current debate about the relationship between autism and vaccinations, especially the triple measles, mumps and rubella (MMR) vaccine. A chapter on HIV and the patient as expert is reprinted from the earlier volume on technology. What is at stake with each of these topics is the fundamental uncertainty of medicine as science and its clumsiness as succour.

The authors write as patients as well as sociologists, and the chapter on MMR, on which subject Collins and Pinch have diametrically opposed attitudes, is particularly effective. It has to be said that the authors want medicine to be more scientific, not less so. Their volume is hardly a plea for alternative medicine or even for the uncritical democratization of conventional medicine. Rather, it is an analysis of the problems of contemporary medical knowledge, and is stronger on diagnosis than on prescription. The authors offer stringent critiques of modern medicine's inadequacies, but are reluctant to suggest what might be done to change it for the better.
This detachment was also present in the earlier volumes and stems, I think, from their attitude towards the nature of 'expertise'. Their discussion of HIV makes a strong case for sufferers having their own kind of expertise, and this may not be simply about the subjective nature of their illness. Many AIDS activists became expert in the nuances of retroviruses, how antiviral drugs work and the design of clinical trials. But as Collins and Pinch point out, meaningful dialogue about scientific issues requires that both parties know what they are talking about. The Internet may not be the best place to acquire expertise, for its unregulated nature most starkly exposes the difficulties of democratic knowledge.

The authors have selected their topics reasonably well, but there are some gaps and curious decisions. The chapter entitled 'Alternative Medicine' is not about alternative medicine at all. It looks at Linus Pauling and Ewan Cameron's advocacy of massive doses of vita$\min \mathrm{C}$ as a treatment for cancer. Pauling and Cameron worked entirely within the framework of scientific medicine, offered a testable hypothesis about why vitamin $\mathrm{C}$ might have the effect they postulated, and wanted clinical trials to be done. They disagreed about the actual design and implementation of the trials, and of course about their outcome, but this episode is about scientific, not 'alternative' medicine.

Collins and Pinch's familiar, cosy style may grate on some, but their purpose is highminded. They have in fact discovered what the Hippocratics knew more than two millennia ago: "Life is short and art long, the occasion fleeting; experience fallacious, and judgement difficult.

W. F. Bynum is at the Wellcome Trust Centre for the History of Medicine, University College London, 210 Euston Road, London NW1 2BE, UK.

IMAGE

UNAVAILABLE FOR COPYRIGHT REASONS 